\title{
Attitudes of Polish Physicians and Medical Students toward Breaking Bad News, Euthanasia and Morphine Administration in Cancer Patients
}

\author{
Wojciech Leppert • Mikolaj Majkowicz • Maria Forycka
}

Published online: 3 October 2013

(C) The Author(s) 2013. This article is published with open access at Springerlink.com

\begin{abstract}
Medical students and physicians should possess basic knowledge concerning medical ethics and palliative care. The aim of the study was to explore the knowledge on the end-of-life ethics and palliative care in third-year medical students and physicians during internal medicine specialty training and their attitude towards breaking bad news and euthanasia. A voluntary and anonymous questionnaire survey with the participation of 401 students and 217 physicians filled after lectures concerning ethics for medical students and after palliative medicine course for physicians during internal medicine specialty training. A total of $28 \%$ students and $24 \%$ physicians $(p=0.282)$ were ready to reveal full information to advanced cancer patients. A total of $82 \%$ of students and $90 \%$ of physicians ( $p=0.008$ ) would not practice euthanasia; $67 \%$ of students and $75 \%$ of physicians ( $p=$ 0.039 ) were opponents of euthanasia legalisation. A total of $70 \%$ doctors and $23 \%$ students indicated oral as the most preferable route of morphine administration. A total of $74 \%$ physicians and $43 \%$ students stated that there is no maximal dose of morphine; $64 \%$ of doctors and $6 \%$ of students indicated constipation as a constant adverse effect of morphine. Breaking bad news is a significant difficulty for both students and physicians. There is a small percentage of those tending to practice euthanasia and bigger accepting its legalisation with fewer physicians than students. In contrast
\end{abstract}

This article was also published in part in Polish: Leppert W, Luczak J, Góralski P. Wybrane problemy opieki paliatywnej i eutanazji w opiniach lekarzy i studentów medycyny. Pol Med Paliat 2005; 4:67-76.

W. Leppert $(\bowtie) \cdot$ M. Forycka

Chair and Department of Palliative Medicine, Poznan University of

Medical Sciences, Osiedle Rusa 25 A, 61-245 Poznan, Poland

e-mail: wojciechleppert@wp.pl

M. Majkowicz

Department of Quality of Life Research, Gdansk Medical University, Gdansk, Poland to medical students, the majority of physicians have knowledge concerning chronic morphine use in the treatment of cancer patients.

Keywords Breaking Bad News · Euthanasia $\cdot$ Morphine · Palliative care

\section{Introduction}

With the growing number of cancer patients and those suffering from other chronic diseases that cannot be subjected effectively to causal treatment, and with the ageing of society, the number of patients demanding palliative care in Poland increases. On the grounds of the number of deaths caused by chronic diseases reaching over 300,000 (including 95,000 from cancer) a year it is possible to roughly estimate that at least approximately 200,000 patients demand palliative care in Poland annually. In recent years, a rapid development is observed in palliative and hospice care in Poland (442 units registered in 2012) with establishing a medical specialty in palliative medicine and nursing specialty in palliative care [1]. However, the amount of centres providing high quality care is still insufficient and the access, especially to palliative care in-patient units in small towns and rural areas is unsatisfactory [2].

Poland is a country with a predominantly catholic faith which has a significant impact on the Polish society's approach on breaking bad news to cancer patients, end-of-life care and euthanasia issues. In recent years of a transition from communist regime to democracy, Poland became more similar to western European countries that generally represent a more open approach in discussions about cancer diagnosis and prognosis with patients and more liberal approach, i.e. a higher acceptance rate of euthanasia legalisation and practice. However, according to the Polish law, euthanasia and assisted 
suicide are banned and their practice results in criminal prosecution [3].

Both medical students and physicians should know the basics of palliative medicine and bioethics principles. Because of diversity in the contents of palliative medicine curricula for students at medical universities and a small number of hours allocated within this field of science to teaching physicians during specialty trainings, the knowledge on the subjects is still unsatisfactory. The aims of the study were to assess the level of knowledge on palliative care, end-of-life ethics and morphine use in pain management, as well as to establish attitudes towards breaking bad news and euthanasia among the two surveyed groups: the third-year medical students and physicians during internal medicine specialty training.

\section{Participants and Methods}

The study concerned four issues:

1. The manner and techniques to facilitate breaking bad news by physicians and students to their patients and the patients' relatives.

2. The recognition of the definition of euthanasia and the doctrine of the double effect, the possible readiness among the physicians and students to practice euthanasia; and the issue of supporting the legalisation of euthanasia in Poland.

3. Defining the terms of suffering, pain, palliative care and a hospice.

4. The knowledge of the basic rules of morphine administration.

The questionnaire (see attachment) was constructed by authors and included 13 questions as follows: conveying the truth about an illness and a prognosis (questions 1-4), attitudes toward practice and legalisation of euthanasia (6-8), descriptive questions regarding euthanasia (5) and the doctrine of double effect (9), definitions of suffering and pain (10), palliative care (11), and hospice (12). The last part of the questionnaire consisted of multiply choice questions with reference to the ways of administration and adverse effects of morphine (13). The pilot-testing of the questionnaire was conducted on 20 third-year medical students and 10 physicians during internal medicine training, which demonstrated that the questionnaire was well accepted and understood.

Questionnaires were to be filled in anonymously and voluntarily directly after both students and physicians courses completion within the time of $45 \mathrm{~min}$. Before filling in the questionnaires, the aim of the study was presented to encourage honest answers to all questions. The questionnaires were administered to two groups of participants:

- The first group constituted of 401 third-year medical students of the Faculty of Medicine at the Poznan University of Medical Sciences, after having attended 20-h obligatory lectures in bioethics (in 2001 and 2002). The basic problems and issues in bioethics were discussed in the programme of the studies, together with the analysis of the doctrine of the double effect and the definition of euthanasia, including the 2-h lecture on "physician facing dying patient". However, the training did not cover the knowledge about the ways of administration and adverse effects of morphine.

- The second group constituted of 217 physicians from different parts of Poland during internal medicine specialty training in 2002 organised in Krakow by a Polish journal Medycyna Praktyczna ("Practical Medicine") and after having attended an 18-h obligatory course in palliative medicine covering lectures on basics of palliative care and ethical problems in end-of-life care.

The ethical approach based on the Christian values in which patients are cared for to the natural end-of-life without any attempts of shortening the patients' life, i.e. euthanasia or assisted suicide was presented to both groups of participants. All patients are provided with a holistic palliative care approach comprising meticulous assessment and symptomatic treatment of physical symptoms including palliative sedation if symptoms are intractable and psychosocial and spiritual support offered to all patients and their families.

The statistical evaluation of the physicians' and students' demographic data was conducted with the chi-square test and the Student's $t$ test (Table 1). The percentage of responses for each question was compared between physicians and students using the difference in proportions test (Tables 2-7). The data were analysed with the licenced statistical package StatSoft,
Table 1 Demographics data of physicians and students

\begin{tabular}{|c|c|c|c|c|}
\hline & & Physicians ( $n=217$ ) & Students $(n=401)$ & $p$ Value \\
\hline \multicolumn{2}{|c|}{ Age years, mean $\pm \mathrm{SD}$} & $32.3 \pm 5.5$ & $23.1 \pm 2.2$ & $0.00001 *$ \\
\hline \multicolumn{5}{|l|}{ Gender $(n)$} \\
\hline \multirow{4}{*}{$\begin{array}{l}\text { Male/female (\%) } \\
\text { Religion } n(\%)\end{array}$} & & $65 / 152(31 \% / 69 \%)$ & $112 / 289(28 \% / 72 \%)$ & \multirow{4}{*}{$\begin{array}{l}0.595 * * \\
0.368 * *\end{array}$} \\
\hline & Catholic & $163(75 \%)$ & $288(72 \%)$ & \\
\hline & Other & $26(12 \%)$ & $44(11 \%)$ & \\
\hline & Atheists & $28(13 \%)$ & $69(17 \%)$ & \\
\hline
\end{tabular}

*Student's $t$ test

${ }^{* *}$ Chi-Square test 
Table 2 Is it always right to inform patients about incurable disease?

\begin{tabular}{lccc}
\hline & $\begin{array}{l}\text { Physicians } \\
(n=217)\end{array}$ & $\begin{array}{l}\text { Students } \\
(n=401)\end{array}$ & $\begin{array}{l}p \\
\text { Value }\end{array}$ \\
\hline Yes & $52(24 \%)$ & $113(28 \%)$ & 0.282 \\
No & $83(38 \%)$ & $120(30 \%)$ & $\mathbf{0 . 0 4 3}$ \\
$\begin{array}{l}\text { It depends on patient's ability to cope } \\
\quad \text { with the disease }\end{array}$ & $80(37 \%)$ & $156(39 \%)$ & 0.625 \\
\begin{tabular}{l} 
No answer \\
\hline
\end{tabular} & $2(1 \%)$ & $12(3 \%)$ & 0.113 \\
\hline
\end{tabular}

Inc. (2011), STATISTICA PL (data analysis software system), version $10^{\circledR}$ www.statsoft.com and StatsDirect statistical software, version 2.6.5 ${ }^{\circledR}$ (2007-11-12). The $p$ value of 0.05 was considered significant. The Local Bioethics Committee at Poznan University of Medical Sciences waived the need for the ethical approval of the study protocol as the questionnaire survey did not concern patients.

\section{Results}

Similar percentage of physicians (7\%; 16 from 233$)$ and students $(6 \%$; 26 from 427) refused to participate. Respondents' basic demographics are submitted in Table 1. Physicians were older than students; a similar percentage of males and females and religion preferences in physicians and students were found. The majority of respondents were Catholics.

\section{Breaking Bad News}

The answers to the question "Is it always right to inform the patient about an incurable disease and unfavourable prognosis?" are shown in Table 2 . Over $35 \%$ of physicians and students subjected making the decision to circumstances, i.e. whether the content of the information could adversely influence the patient's ability to continue the fight with the disease. To a question "Who should be given bad news first?" $53 \%$ of the physicians and $55 \%$ of the students indicated that bad news should be given first to patients; $28 \%$ and $32 \%$, respectively, stated that bad news should be given to patients' relatives first. The choice whether to break bad news to patients or relatives first, for $10 \%$ of physicians and $12 \%$ of the students surveyed, depends on many factors, which have to be considered before making the final decision. The age of a
Table 4 Would you like to be informed in case of an incurable disease?

\begin{tabular}{lrrl}
\hline & Physicians $(n=217)$ & Students $(n=401)$ & $p$ Value \\
\hline Fully & $174(80 \%)$ & $337(84 \%)$ & 0.211 \\
Partially & $30(14 \%)$ & $56(14 \%)$ & 1.0 \\
No answer & $13(6 \%)$ & $8(2 \%)$ & $\mathbf{0 . 0 0 9}$ \\
\hline
\end{tabular}

patient and his psychological condition were admitted to be the most important.

For a question "How bad news should be given?" the answers are shown in Table 3. A total of $19 \%$ of the physicians and $11 \%$ of the students subjected making the decision in this matter to the mental condition of the patient. To the question "If you were suffering from an incurable disease would you like to be fully or partly informed about it?" decided majority of the physicians $(80 \%)$ and the students ( $84 \%$ ) would like to be fully informed about the unfavourable prognosis (Table 4).

\section{Euthanasia and the Doctrine of Double Effect}

Euthanasia was defined by $36 \%$ of the physicians and $37 \%$ of the students as "a murder or a life termination, acceleration of death of a person suffering from an incurable disease with the patient's consent (to her/his request or wish)". Other definitions given by physicians: "the good (dignified) death" (12\%), "painless termination of life of an incurably ill patient" (11\%), "homicide (murder)" (6\%), "assistance in dying" (5\%), "homicide on request" (5\%). Students described euthanasia as "termination of life of an incurable person" (12\%), "good death" (5\%), "a murder" (4\%), without giving compassion for its motive. Most physicians and students would not commit euthanasia or assisted suicide (Table 5). In case of incurable disease, over $70 \%$ of physicians and students chose natural death (Table 6). Majority of physicians and students responded negatively to the possibility of euthanasia legalisation (Table 7).

To the question "Describe the doctrine of double effect" $47 \%$ of the physicians and $88 \%$ of the students did not answer. Physicians described the term as "a death-resulting side effect caused by administering medicine in good faith" (19\%); "causing any unintended side effect by administering medicine" (23\%); "any action causing a good or bad side effect" (5\%); "means causing any side effect by administering
Table 3 How bad news should be given

\begin{tabular}{lccc}
\hline & Physicians $(n=217)$ & Students $(n=401)$ & $p$ Value \\
\hline Fully & $87(40 \%)$ & $237(59 \%)$ & $\mathbf{0 . 0 0 0 0 1}$ \\
Partially & $82(38 \%)$ & $116(29 \%)$ & $\mathbf{0 . 0 2 2}$ \\
It depends on patient's mental condition & $41(19 \%)$ & $44(11 \%)$ & $\mathbf{0 . 0 0 6}$ \\
No answer & $7(3 \%)$ & $4(1 \%)$ & 0.067 \\
\hline
\end{tabular}


Table 5 Would you commit an act of euthanasia or assisted suicide?

\begin{tabular}{lccc}
\hline & Physicians $(n=217)$ & Students $(n=401)$ & $p$ Value \\
\hline Yes & $11(5 \%)$ & $48(12 \%)$ & $\mathbf{0 . 0 0 5}$ \\
No & $195(90 \%)$ & $329(82 \%)$ & $\mathbf{0 . 0 0 8}$ \\
Don't know & $11(5 \%)$ & $24(6 \%)$ & 0.607 \\
\hline
\end{tabular}

medicine or applying medical procedure" (4\%); "means to administer an analgesic accelerating death" (3\%).

\section{Definitions of Suffering, Pain, Palliative Care and Hospice}

The most common definition of suffering and pain was "it is a feeling of unease, discomfort" without either the distinction between pain and suffering or the indication of their effect on patient's life ( $14 \%$ of the physicians, $22 \%$ of the students). Other more frequent answers included the following: "Pain is a physical experience, whereas suffering is a combination between physical pain and spiritual and mental experience" (13\% and $17 \%$, respectively); "Pain has a physical nature, suffering is a mental experience" (12\% and $15 \%$ respectively), respectively; "Pain and suffering is an experience occupying patient's attention completely making it impossible to lead a normal life" (12\% and $16 \%$, respectively).

For $49 \%$ of the physicians and $51 \%$ of the students, palliative care is "care for incurable patients' improving their comfort of life". Other physicians definitions are as follows: "a number of medical and psychological treatments applied to incurable patients" ( $9 \%$ ), "help provided to an incurable patient and his family, with the family's cooperation, in each aspect of his/her life" (6\%), "a treatment of a cancer patient" (4\%), "care for the chronically ill" (3\%). Students defined the term as "care concentrating on relieving the pain and on psychological support" (9\%), "help with gentle, painless dying" (5\%), "all methods and treatment procedures used in order to relieve pain" ( $6 \%$ ), "care for the terminally ill, based on relief of disease symptoms without causal treatment" (4\%), "care for the patients, the disabled, who cannot function without it" (2\%).

For $35 \%$ of the physicians and $37 \%$ of the students, the word hospice meant "a place where incurably ill patients stay"; other physicians' opinions are the following: it is "a

Table 6 In case of incurable disease would you like to choose

\begin{tabular}{lrcc}
\hline & Physicians $(n=217)$ & Students $(n=401)$ & $p$ Value \\
\hline Natural death & $167(77 \%)$ & $289(72 \%)$ & 0.177 \\
Euthanasia & $26(12 \%)$ & $76(19 \%)$ & $\mathbf{0 . 0 2 5}$ \\
Assisted suicide & $9(4 \%)$ & $20(5 \%)$ & 0.573 \\
Don't know & $15(7 \%)$ & $16(4 \%)$ & 0.104 \\
\hline
\end{tabular}

Table 7 Are you in favour of euthanasia legalisation

\begin{tabular}{lccc}
\hline & Physicians $(n=217)$ & Students $(n=401)$ & $p$ Value \\
\hline Yes & $37(17 \%)$ & $104(26 \%)$ & $\mathbf{0 . 0 1 1}$ \\
No & $163(75 \%)$ & $269(67 \%)$ & $\mathbf{0 . 0 3 9}$ \\
Don't know & $17(8 \%)$ & $28(7 \%)$ & 0.649 \\
\hline
\end{tabular}

concrete form of help and care for incurably ill people" (18\%), "dignified death" (6\%), "persons taking care of terminally ill patients" (6\%), "dying patients" (3\%), "death" (3\%), and "home, warmth, hospitality and human goodness" (4\%). The students answers included the following: "a form of help and care for the terminally ill" ( $9 \%$ ), "dignified dying" ( $9 \%)$, "dying patients" (5\%), "a hospital caring for terminally ill patients" (4\%), "physical and mental preparation for death" (4\%), and "death" (2\%).

\section{Basic Principles of Morphine Administration}

To the question of the most proper route of morphine administration, the physicians indicated oral $(70 \%)$, oral and subcutaneous ( $7 \%$ ), subcutaneous ( $5 \%$ ), and oral, subcutaneous and intravenous (3\%); $2 \%$ agreed that all routes are correct. Among students $23 \%$ indicated an oral route as the most preferable, an intravenous (33\%), subcutaneous and intramuscular $-12 \%$ each. A total of $12 \%$ of the physicians and $51 \%$ of the students responded positively to the question: "Is it always wrong to exceed a certain doses of morphine?" with $74 \%$ and $43 \%$ respectively, who disagreed with this statement.

With regard to morphine adverse effects, most physicians $(64 \%)$ and few students $(6 \%)$ chose the right answer that morphine is causing constipation. According to $5 \%$ of the physicians and $25 \%$ of the students, morphine causes all listed adverse effects. Remaining answers combined a number of side effects of morphine included in the survey, $17 \%$ of the physicians and $12 \%$ of the students did not return an answer. To a question "Should morphine be prescribed only to the patients who will die soon?" $82 \%$ of the physicians and $85 \%$ of the students gave a negative answer to this question, whereas 3 and $8 \%$, respectively, replied that morphine should only be administered to dying patients.

\section{Discussion}

The study concerned several important aspects of palliative care such as breaking bad news to incurable patients, attitudes toward euthanasia, knowledge of key terms in the care of patients with advanced diseases (suffering, pain, palliative care, hospice), ethical problems (euthanasia, the doctrine of 
double effect) and basic knowledge on morphine administration. To our knowledge, this is the first study that attempted to look at so many key aspects in the care for patients with advanced diseases from the perspective of physicians during internal medicine specialty training and third-year medical students.

\section{Breaking Bad News}

The percentage of respondents who would always inform the patient about unfavourable prognosis was similar among physicians ( $28 \%)$ and students (24\%). However, the answer "no" was more often provided by physicians $(p=0.043)$; this was also the case for all answers to how should bad news be given as physicians less often indicated full information $(p=$ $0.00001)$, more often pointed partial information $(p=0.022)$ or the information dependent on patient's psychological state $(p=0.006)$. Interestingly, in case of own incurable disease, a similar and decided majority of physicians and students ( 80 and $84 \%$, respectively) would like to be fully informed about the unfavourable prognosis. Several possible explanations might be considered for this discrepancy. One may be that not only physicians, but also students, may will to protect patients from a possible negative impact of bad news on their psychological state. Another explanation might be that own incurable disease is a hypothetic situation and the will of physicians and students may change with respect to information needs. These differences in physicians' and students' approaches indicate a more conservative and more cautious approach of physicians who takes into account possible psychological consequences of bad news provision [4].

A change in breaking bad news in patients with unfavourable prognosis to a more open approach was observed in studies conducted in Poland. According to the current law, patients have the right to be informed about their health state, the diagnosis and the prognosis (not at the time the study was conducted). The rise of positive opinions in society concerning the need of informing cancer patients about the favourable as well as the unfavourable prognosis, though in the second case, the rise is lower, was found [5]. In a Polish study $3 \%$ of the physicians would fully break bad news and $76 \%$ to this degree, so as to leave hope to the patient [6]. In another study $84 \%$ physicians stated that the patient should be informed about his unfavourable prognosis, $4 \%$ was of an opposite opinion, and $11 \%$ would not break bad news whatsoever [7]. In Norway, from a random sample of 990 physicians, $81 \%$ reveal full information to the patient concerning cancer diagnosis [8]. In Portugal, from 45 oncologists, $71 \%$ disclose diagnosis always or at the patients' request [9].

With respect to fifth- and sixth-year Polish medical students, $80 \%$ would provide the patient with the information about the unfavourable prognosis, $10 \%$ would not and another $10 \%$ were of no opinion [7]. In another study, in case of unfavourable prognosis the whole truth would be given by $7 \%$ of Polish, $42 \%$ of German and $4 \%$ of Byelorussian students; the incomplete truth, making if possible, to sustain hope would be given by 53,33 and $78 \%$, respectively; only on patient's request would be given by 31,23 and $13 \%$, respectively and some would not give the information about unfavourable prognosis whatsoever, 9,2 and $7 \%$, respectively [10].

\section{Euthanasia and the Doctrine of Double Effect}

Any majority of the surveyed, both the students and the physicians, gave comprehensive definitions of euthanasia, though the meaning of only a few of the answers was consistent with the Penal Code [3]. A total of $90 \%$ of the physicians and $82 \%$ of the students $(p=0.008)$ would not commit an act of euthanasia or assisted suicide; opposite opinion expressed 5 and $12 \%$, respectively $(p=0.005)$. In the prospect of an incurable disease, the right to choose natural death declared a majority and similar percentage of physicians (77\%) and students $(72 \%)$. However, less physicians (12\%) than students $(19 \%)(p=0.0025)$, would choose euthanasia in this situation. Similarly, more physicians $(75 \%)$ than students $(67 \%)$ were opponents of euthanasia legalisation $(p=0.039)$ and consequently, less supporting of legalising euthanasia (17 and $26 \%$, respectively; $p=0.011$ ).

The results are most probably associated with more ethical maturity of physicians, their clinical experience and older age. The Polish Code of Medical Ethics firmly opposes the concept of euthanasia (31st article: "A physician cannot conduct acts of euthanasia") [11]. The Catholic Church opposes euthanasia [12] as well as The Council of Europe and The European Court of Human Rights [13]. According to the Penal Code, euthanasia in Poland is illegal [3]. During courses for both physicians and students, euthanasia and assisted suicide were condemned and palliative care was presented as an alternative [14]. All these factors might have influenced the results obtained [15].

In the study conducted among 30 home hospice patients, 70 physicians, 60 fifth-year and 60 sixth-year medical students, and 50 citizens concerning euthanasia legalisation $53 \%$ of interviewees replied negatively, $31 \%$ positively and $16 \%$ had no opinion. Mostly, young people (below 35) were for the legalisation of euthanasia. Groups against euthanasia included patients $(73 \%)$, physicians (55\%), citizens $(48 \%)$ and students (45\%). The possibility of performing euthanasia on themselves, in case of incurable illness, was taken into consideration by $9 \%$ physicians, $20 \%$ students and $42 \%$ citizens. Most of the people interviewed rejected such possibility or were of no opinion [7]. In a comparative study, the acceptance for euthanasia among the first-year Polish medical students was significantly lower $(48 \%)$ than Swedish $(61 \% ; p<0.007)$ and German $(82 \% ; p<0.0001)$ students [16]. 
The doctrine of double effect relates to the use of opioids and sedatives to relieve intractable symptoms, e.g. pain, dyspnea and induce palliative sedation in patients approaching death [17]. If the physician administers drugs in accordance with the rules of titration intending to relieve suffering and not to shorten the patient's life, and adverse effects could attribute to shortening the patient's life, this excludes the physician's action as illegal, thus it does not constitute euthanasia. Administering opioids and sedatives may be necessary to alleviate patient's suffering called palliative sedation [18]. In this study, $19 \%$ of physicians described the doctrine of double effect correctly as "causing death as an adverse effect of wellintentioned administering of a drug"; $47 \%$ physicians and $88 \%$ students did not reply which indicates poor knowledge on this topic, especially among students.

Definitions of Suffering, Pain, Palliative Care and Hospice and Basic Principles of Morphine Administration

To $49 \%$ of physicians and $51 \%$ of students, palliative care meant, "care for incurably ill people improving comfort of their life". The rest of the surveyed provided other definitions of palliative care. According to the World Health Organization, "Palliative care is an approach that improves quality of life of patients and their families facing the problem associated with life-threatening illness, through the prevention and relief of suffering by means of early identification and impeccable assessment and treatment of pain and other problems, physical, psychosocial and spiritual" [19]. The notion of palliative care was known to $100 \%$ of the physicians and medical students surveyed and to $25 \%$ of citizens of Podlaskie Province, Poland [7]. The definitions of pain given by the surveyed differed significantly from the definition provided by the International Association for the Study of Pain [20].

With respect to the most proper route of morphine administration, the majority of physicians answered oral $(70 \%)$ while only $23 \%$ of the students provided the same answer. To the question "Is it always wrong to exceed a defined dosage of morphine?" $12 \%$ of physicians and $51 \%$ of students replied positively. A total of $74 \%$ of the physicians and $43 \%$ of the students gave the correct answer, that there is not any maximum dose of morphine. To the question about side effects of morphine the correct answer that morphine causes constipation was given by $64 \%$ of the physicians and only $6 \%$ of the students.

These answers clearly indicate that the knowledge on chronic morphine administration for pain and dyspnea management is better in physicians. However, it should be noted that the students had been questioned in this study after only ethical lectures without medical knowledge provision and that they held palliative medicine classes twice on their fifth and sixth year. Thus, it may be assumed that students' knowledge considerably improved with respect to the appropriate use of morphine.
However, some of the gaps on morphine and opioid administration were found in other surveys conducted in Poland. In the study amongst the sixth-year medical students of Wroclaw Medical University conducted before lectures on palliative care, $29 \%$ of them stated that morphine is mostly administered orally; $71 \%$ of respondents pointed to constipation as the main side effect of morphine and $21 \%$ was concerned about respiratory depression [21]. In the survey investigating knowledge about the use of opioids in cancer patients with pain conducted among all family doctors in two provinces in Poland $51 \%$ (195 questionnaires) of answers were obtained. To five questions (with four possible answers and only one correct), an average of $2.2 \pm 1.4$ correct answers was obtained. Younger physicians with shorter practice since obtaining specialisation, better access to a palliative care centre and having knowledge concerning breakthrough pain treatment gave larger number of correct answers [22].

Limitations of the study include a recruitment of students from one academic centre only, one administration of questionnaires on courses completion only without baseline evaluation. Limited number of questions was devoted to each of the explored issues. Furthermore, there was mainly quantitative evaluation for most of the questions without deeper analysis of respondents' motives and reasons for expressed attitudes.

In conclusion, the study results indicate a significant difficulty in providing information to patients regarding diagnosis of incurable disease and unfavourable prognosis. The results indicate also a limited knowledge in the terminology of medical ethics with physicians, a problem exceptionally evident with third-year medical students. This refers also to morphine administration for pain and dyspnea regarding students. However, it is likely to change after completing obligatory courses in palliative medicine on the fifth and sixth year of studies. A small percentage of the physicians and of the students expressed consent to an act of euthanasia and assisted suicide and slightly higher would support euthanasia legalisation with fewer physicians than students.

\section{Questionnaire}

1. Is it always right to inform the patient about an incurable disease and unfavourable prognosis?
a.) Yes
b.) No
c.) It depends on patient's ability to cope with the disease

2. Who should be given bad news first:

a.) The family

b.) The patient

3. How bad news should be given? 

a.) Fully
b.) Partially
c.) It depends on patient's mental condition

4. If you were suffering from a terminal disease would you like to be fully or partly informed about it:
a.) Partly
b.) Fully

5. What does the word euthanasia mean?

6. Would you make a decision of committing an act of euthanasia or assisted suicide:
a.) Yes
b.) No

7. If you or a close person of yours suffered from an incurable disease, would you like to have the right to choose:
a.) Natural death
b.) Euthanasia
c.) Assisted suicide

8. Are you in favour of legalisation of euthanasia or assisted suicide?
a.) Yes
b.) No

9. Describe the doctrine of double effect.

10. Provide you own definition of suffering and pain.

11. Provide the definition of palliative care.

12. What associations do you have with the word hospice?

13. With reference to morphine administered over a long period of time in order to treat pain and/or breathlessness, circle a proper answer:

a.) The most proper route of morphine administration is:

- Oral

- Subcutaneous

- Intramuscular

- Intravenous

- Yes

- No

c.) Morphine usually develops:

- Confusion

- Respiratory depression

- Constipation

- Addiction

d.) Morphine should be prescribed only to the patients who will die soon

- Yes

- No
Open Access This article is distributed under the terms of the Creative Commons Attribution License which permits any use, distribution, and reproduction in any medium, provided the original author(s) and the source are credited.

\section{References}

1. Centeno C, Pons JJ, Lynch T, Donea O, Rocafort J, Clark D (2013) EAPC atlas of palliative care in Europe 2013 - cartographic edition. EAPC Press, Milan, p 91, Poland

2. Leppert W, Luczak J (2007) A holistic approach to palliative care in Poland. Eur J Palliat Care 14:80-83

3. The Penal Code (Act of 6th June 1997). Article 150. § 1. Whoever kills a human being on his demand and under the influence of compassion for him shall be subject to the penalty of the deprivation of liberty for a term of between 3 months and 5 years. $\S 2$. In some extraordinary circumstances the court may apply an extraordinary mitigation of the penalty or even renounce its imposition. Article 151 . Whoever by persuasion or by rendering assistance induces a human being to make an attempt on his own life shall be subject to the penalty of the deprivation of liberty for a term of between 3 months and 5 years.

4. Sepiolo A (1998) The problems of breaking bad news in Poland and in the world (in Polish). Psychoonkologia 2:69-73

5. Jokiel M (1996) Changes in public opinion on informing patients about their cancer diagnosis in 1976, 1986 and 1990 (in Polish). Nowotwory 46:235-240

6. Juczynski Z, Szamburska J, Czechowicz E (1997) Informing about cancer disease in the physicians' opinion and practice (in Polish). Nowotwory 47:43-57

7. Matejuk A, Mikolajczyk E, Lewko A, Abramczyk J, Blasiak T, Rucinska M, Wojtukiewicz MZ (2003) Palliative care or euthanasia - attitudes of patients, physicians, medical students and inhabitants of Podlasie (in Polish). Onkol Pol 6:29-33

8. Loge JH, Kaasa S, Ekberg Ø, Falkum E, Hytten K (1996) Attitudes toward informing the cancer patient - a survey of Norwegian physicians. Eur J Cancer 32:1344-1348

9. Gonçalves F, Castro S (2001) Diagnosis disclosure in a Portuguese oncological centre. Palliat Med 15:35-41

10. Juczynski Z, Schwarz R, Nojek T (2002) Informing about cancer disease in the Polish-German-Byelorussian medical students' opinion (in Polish). Psychoonkologia 6:47-52

11. Polish Code of Medical Ethics (in Polish). Warszawa 12-14 grudnia 1993. Oficyna Wydawnicza Naczelnej Izby Lekarskiej, Warszawa 1994.

12. John Paul II: Evangelium vitae. Rome 1995.

13. Coblence C, Ellenberg E, Guerrier M, Hirsch E (2005) Legal matters concerning euthanasia at European level. Eur J Palliat Care 12:69-73

14. Reczek L (1998) Student of Medical Faculty of Silesian Medical Academy towards the problem of euthanasia (in Polish). Psychoonkologia 2:37-50

15. Leppert W, Gottwald L, Majkowicz M et al (2013) A comparison of attitudes toward euthanasia among medical students at two Polish universities. J Cancer Educ 28:384-391

16. Mierzecki A, Rekawek K, Swiatkowski J et al (2008) Evaluation of attitude towards euthanasia expressed by first year medical students' from Szczecin, Greifswald and Lund medical faculties (in Polish). Ann Acad Med Stetin 54:164-169

17. Radbruch L (2002) Reflections on the use of sedation in terminal care. Eur J Palliat Care 9:237-239

18. Thorns A (1998) A review of the doctrine of double effect. Eur J Palliat Care 5:117-120 
19. Sepúlveda C, Marlin A, Yoshida T, Ullrich A (2002) Palliative care: the World Health Organisation's global perspective. J Pain Symptom Manage 24:91-96

20. IASP Subcommittee on Taxonomy (1979) Pain terms: a list with definitions and notes of usage. Pain 6:247-252

21. Oronska A, Wozniak SP (2005) What 6th year medical students know about cancer pain treatment. Abstracts of the 9th
Congress of the European Association for Palliative Care, Aachen, Germany, 8-10 April 2005. Eur J Palliat Care, Hayward Medical Communications, pp 41-42

22. Buczkowski K, Krajnik M, Budzynski J, Chlabicz S (2004) Family physicians' knowledge about opioid therapy in province of Kujawy-Pomorze and Podlasie (in Polish). Pol Med Paliat 3: $335-342$ 